University of Nebraska - Lincoln

DigitalCommons@University of Nebraska - Lincoln

Conflicting Patterns of Genetic Structure Produced by Nuclear and Mitochondrial Markers in the Oregon Slender Salamander (Batrachoseps wrighti): Implications for Conservation Efforts and Species Management

\author{
Mark P. Miller \\ Utah State University, markperrymiller@gmail.com \\ Susan M. Haig \\ U.S. Geological Survey, Susan_Haig@usgs.gov \\ Steven Wagner \\ Oregon State University
}

Follow this and additional works at: https://digitalcommons.unl.edu/usgsstaffpub

Miller, Mark P.; Haig, Susan M.; and Wagner, Steven, "Conflicting Patterns of Genetic Structure Produced by Nuclear and Mitochondrial Markers in the Oregon Slender Salamander (Batrachoseps wrighti): Implications for Conservation Efforts and Species Management" (2005). USGS Staff -- Published Research. 673.

https://digitalcommons.unl.edu/usgsstaffpub/673

This Article is brought to you for free and open access by the US Geological Survey at DigitalCommons@University of Nebraska - Lincoln. It has been accepted for inclusion in USGS Staff -- Published Research by an authorized administrator of DigitalCommons@University of Nebraska - Lincoln. 


\title{
Conflicting patterns of genetic structure produced by nuclear and mitochondrial markers in the Oregon slender salamander (Batrachoseps wrighti): Implications for conservation efforts and species management
}

\author{
Mark P . Miller ${ }^{1, *, \dagger}$, Susan M . Haig ${ }^{2}$ \& R. Steven Wagner ${ }^{3, \dagger}$ \\ ${ }^{1}$ Department of Biology, 5305 Old Main Hill, Utah State University, Logan, UT 84322-5305, USA; ${ }^{2} U S G S$ \\ Forest and Rangeland Ecosystem Science Center, 3200 SW Jefferson Way, Corvallis, OR 97331, USA; \\ ${ }^{3}$ Genetics Program, Oregon State University, Corvallis, OR 97331 and Department of Biological Science, \\ Central Washington University, Ellensburg, WA 98926, USA (*Corresponding author: Fax: + 1-435-797- \\ 1575; E-mail: Mark.Miller@usu.edu)
}

Received 12 April 2004; accepted 2 June 2004

Key words: Batrachoseps wrighti, conservation genetics, forest management, Oregon slender salamander, population structure

\begin{abstract}
Endemic to Oregon in the northwestern US, the Oregon slender salamander (Batrachoseps wrighti= $B$. wrightorum) is a terrestrial plethodontid found associated with late successional mesic forests. Consequently, forest management practices such as timber harvesting may impact their persistence. Therefore, to infer possible future effects of these practices on population structure and differentiation, we used mitochondrial DNA sequences (cytochrome $b$ ) and RAPD markers to analyze 22 populations across their range. Phylogenetic analyses of sequence data (774 bp) revealed two historical lineages corresponding to northern and southern-distributed populations. Relationships among haplotypes and haplotype diversity within lineages suggested that the northern region may have more recently been colonized compared to the southern region. In contrast to the mitochondrial data, analyses of 46 RAPD loci suggested an overall pattern of isolation-by-distance in the set of populations examined and no particularly strong clustering of populations based on genetic distances. We propose two non-exclusive hypotheses to account for discrepancies between mitochondrial and nuclear data sets. First, our data may reflect an overall ancestral pattern of isolation-by-distance that has subsequently been influenced by vicariance. Alternately, our analyses may suggest that male-mediated gene flow and female philopatry are important contributors to the pattern of genetic diversity. We discuss the importance of distinguishing between these two hypotheses for the purposes of identifying conservation units and note that, regardless of the relative contribution of each mechanism towards the observed pattern of diversity, protection of habitat will likely prove critical for the long-term persistence of this species.
\end{abstract}

\section{Introduction}

The dynamics of population divergence and reticulation can be revealed through phylogeographic investigations (Avise et al. 1987; Avise 1994). These studies focus on relationships among

${ }^{\dagger}$ Both authors contributed equally to the content of this manuscript. populations and provide information concerning historical patterns of diversity. Often, they identify geographic features as the prime source of genetic structuring (Lamb et al. 1989; Avise 1992; Phillips 1994; Routman et al. 1994; Phillips et al. 2000). In the northwestern United States, the biogeography of the region was shaped by a complex history of glaciation, flooding, and volcanism during the late 
Pliocene (5-3 mya) with the rise of the High Cascades (Baker and Barker 1985; McGroder 1991). During this period, the assembled mesic forest communities that dominate the region became fragmented. As such, historical fragmentation of habitats throughout this landscape has likely produced strong patterns of genetic structure in many forest-associated species.

Concomitant with identification of biogeographical factors that influence distributions of genetic variation across landscapes, it is critical to understand genetic data within the context of ecological and life history traits of the organism under investigation. Organismal attributes of primary importance include dispersal behavior, which is perhaps the most commonly investigated ecological characteristic used to interpret patterns of genetic divergence (e.g., Bohonak 1999; Miller et al. 2002). Dispersal patterns of northwest mesic forest-associated organisms are influenced by historical biogeographic boundaries as well as current processes of forest fragmentation (i.e., timber harvests and rural development; US Forest Service and US Bureau of Land Management 1994). Subsequently, mature forest-associated species with limited dispersal capabilities may be severely impacted by this increased fragmentation.

Endemic to the western slopes of the Oregon Cascades, the Oregon slender salamander (Batrachoseps wrighti) is a species of concern with respect to the Northwest Forest Management Plan (US Forest Service and US Bureau of Land Management 1994). Further, they are classified as "sensitive" in Oregon (Oregon Department of Fish and Wildlife 1997). Characterized by a completely terrestrial life history, they are mostly associated with moist woody debris, older decay classes of logs, and are occasionally found in talus slopes (Nussbaum et al. 1983; Bury and Corn 1988; Gilbert and Allwine 1991). The Oregon slender salamander can be locally abundant in mature forests; however, the species is rare in second growth or clear-cuts (Bury and Corn 1988; Gilbert and Allwine 1991). Consequently, forest management practices may potentially lead to local extirpation and could affect overall species viability (Marshall et al. 1992).

Many aspects of Oregon slender salamander life history may influence their susceptibility to habitat fragmentation. These traits include low reproductive rate (delayed onset of female oviposition until 4-5 years of age, clutch size averages 6.3 eggs, clutch frequency and survivorship are unknown; Tanner 1953) and presumed low rates of dispersal. Although there have been few studies of dispersal, movement, and home range size in slender salamanders (Genus Batrachoseps, summarized in Stebbins and Cohen 1995), home range size of the California slender salamander (B. attenuates) was observed to have a diameter of only $1.7 \mathrm{~m}$ (Hendrickson 1954). Thus, home range size and dispersal are also thought to be limited in the Oregon slender salamander.

As a first step towards understanding fragmentation in the context of historical processes, we investigated geographic variation and population genetic structure in the mature forest-associated Oregon slender salamander using two molecular marker systems: mtDNA cytochrome $b$ sequences and random amplified polymorphic DNA (RAPD). Cytochrome $b$ sequences have proven to be a useful marker to infer intra-specific phylogenies in many salamander species (e.g., Moritz et al. 1992; Tan and Wake 1995; Jockusch 1996; Jackman et al. 1997; Alexandrino et al. 2000) and in a number of other taxa to define conservation units (Walker et al. 1998; Doukakis et al. 1999; Wood and Raley 2000; Haig et al. in press). The RAPD technique is a simple and cost effective procedure for evaluating large numbers of putative segregating nuclear loci. RAPDs have been extensively used in studies of vertebrates to investigate population structure and assist with the development of conservation strategies (e.g., Kimberling et al. 1996; Prior et al. 1997; Cooper 2000, Haig et al. 2001).

\section{Materials and methods}

\section{Tissue sampling and DNA isolation}

Oregon slender salamanders were sampled from 22 localities throughout their known range (Figure 1 and Table 1). Salamanders were hand-captured and sample tissue was taken by non-lethal tail clipping (approximately $1 \mathrm{~cm}$ ), using different sterile surgical scissors for each individual. After sampling, animals were promptly released precisely where they were captured. Sample tissue was placed immediately in a cryogenic tube containing buffer solution (100 mM Tris- $\mathrm{HCl}$ pH 8.0, 


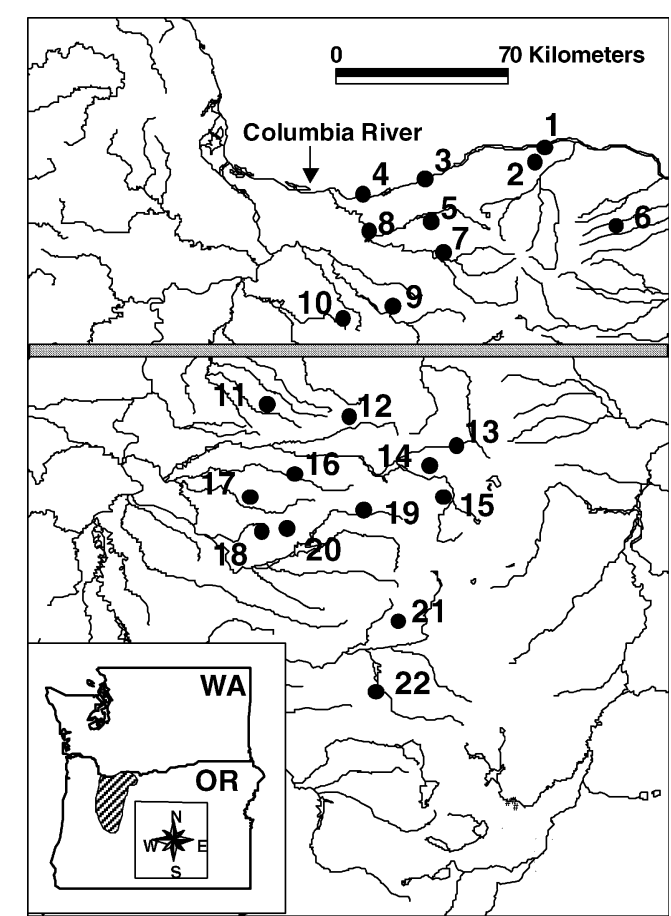

Figure 1. Map of Oregon slender salamander collection locations in northwestern Oregon, USA. Additional information about each location is provided in Table 1 . The shaded horizontal line across the map divides sites into two groups based on relationships of haplotypes.

100 mM EDTA pH 8.0, 10 mM NaCl, 0.5\% SDS) until transferred to an ultracold freezer $\left(-80{ }^{\circ} \mathrm{C}\right)$.
DNA was isolated using a modified phenol/chloroform extraction procedure (Sambrook et al. 1989) and collected over a microcon-50 filter (Millipore). First, $2 \mu \mathrm{g}$ of tissue was digested in $400 \mu \mathrm{l}$ of extraction buffer $(100 \mathrm{mM}$ Tris- $\mathrm{HCl} \mathrm{pH}$ 7.5, $100 \mathrm{mM}$ EDTA, $250 \mathrm{mM} \mathrm{NaCl}$, Proteinase K $600 \mu \mathrm{g} / \mathrm{ml}$ ) overnight at $55^{\circ} \mathrm{C}$. Each sample was extracted twice using equal volumes of phenol equilibrated with Tris- $\mathrm{HCl}$ buffer $(\mathrm{pH} 7.5)$, followed by two chloroform/isoamyl alcohol (25:1) extractions. Finally, the aqueous layer was placed in a microcon-50 filter (Millipore), washed twice with $400 \mu \mathrm{l}$ of TE buffer $(10 \mathrm{mM}$ Tris- $\mathrm{HCl}$, $0.1 \mathrm{mM}$ EDTA, $\mathrm{pH} 8.0$ ), centrifuged again for 5 min $(14,000 \times g)$, then inverted and centrifuged for $30 \mathrm{~s}$ to elute the final DNA solution. Extraction quality was checked using agarose gel electrophoresis. The concentration for each sample was estimated by fluorimetry (Hoefer TKO 100).

\section{MtDNA amplification and analyses}

The polymerase chain reaction (PCR) was used to amplify a $774 \mathrm{bp}$ fragment of the cytochrome $b$ gene, using the following primers designed for vertebrates: MVZ15 (5'-GAACTAATGGCCCACACWWTACGNAA-3') and MVZ16 (5'-AAATAGGAAATATCATTCTGGTTTAAT-3'; Moritz et al. 1992). Three individuals from each of the 22 collection locations were randomly chosen for

Table 1. Collection location information for 22 Oregon slender salamander populations examined in this study

\begin{tabular}{|c|c|c|c|c|}
\hline Population & $M / R$ & Haplotype & Lat., long. & County \\
\hline 1. Post Canyon & $3 / 16$ & A & $-121.616,45.6713$ & Hood River, OR \\
\hline 2. Viento State Park & $3 / 0$ & $\mathrm{~B}$ & $-121.657,45.6278$ & Hood River, OR \\
\hline 3. Ainsworth State Park & $3 / 0$ & $\mathrm{~B}$ & $-122.380,45.5480$ & Multnomah, OR \\
\hline 4. Train Tunnel & $3 / 7$ & $\mathrm{~B}$ & $-122.280,45.5380$ & Multnomah, OR \\
\hline 5. Bull Run & $3 / 17$ & $\mathrm{~B}$ & $-122.034,45.4543$ & Multnomah, OR \\
\hline 6. East Mt. Hood & $3 / 15$ & $\mathrm{C}$ & $-121.368,45.4252$ & Multnomah, OR \\
\hline 7. Wildwood & $3 / 16$ & $\mathrm{~B}$ & $-121.993,45.3536$ & Wasco, OR \\
\hline 8. N. Eagle Creek & $3 / 13$ & $\mathrm{D}$ & $-122.264,45.4223$ & Clackamas, OR \\
\hline 9. Estacada & $3 / 20$ & $\mathrm{E}$ & $-122.276,45.6380$ & Clackamas, OR \\
\hline 10. Jackson Five & $3 / 26$ & $\mathrm{~F}$ & $-122.347,45.1617$ & Clackamas, OR \\
\hline 11. Silver Creek Falls & $3 / 9$ & G & $-122.630,44.8899$ & Marion, OR \\
\hline 12. Detroit Lake & $3 / 14$ & $\mathrm{H}$ & $-122.275,44.5676$ & Marion, OR \\
\hline 13. Little Santiam & $3 / 19$ & I & $-122.329,44.8499$ & Marion, OR \\
\hline 14. Breitenbush & $3 / 0$ & $\mathrm{~J}$ & $-121.941,44.7604$ & Marion, OR \\
\hline 15. Bugaboo & $3 / 7$ & $\mathrm{~K}$ & $-121.981,44.6040$ & Linn, OR \\
\hline 16. Thomas Creek & $3 / 26$ & $\mathrm{~L}, \mathrm{M}$ & $-122.532,44.6834$ & Linn, OR \\
\hline
\end{tabular}


Table 1. (Continued)

\begin{tabular}{lllll}
\hline Population & $M / R$ & Haplotype & Lat., long. & County \\
\hline 17. Church Creek & $3 / 15$ & $\mathrm{~N}$ & $-122.696,44.6100$ & Linn, OR \\
18. Keel Over & $3 / 28$ & $\mathrm{O}$ & $-122.651,44.5137$ & Linn, OR \\
19. Quartzville & $3 / 21$ & $\mathrm{P}$ & $-122.275,44.5676$ & Linn, OR \\
20. Withycomb & $3 / 21$ & $\mathrm{P}$ & $-122.555,44.5187$ & Linn, OR \\
21. H.J. Andrews & $3 / 21$ & $\mathrm{Q}$ & $-122.155,44.2322$ & Lane, OR \\
22. Hidden Lake & $3 / 28$ & $\mathrm{R}$ & $-122.235,44.0144$ & Lane, OR \\
\hline
\end{tabular}

Population numbers correspond to locations in Figure 1. $M$ and $R$ are the number of individuals analyzed for mitochondrial sequence and RAPD variation, respectively. Letters in the "Haplotype" column correspond to one of 18 unique haplotypes detected in this study (Table 2 ).

sequence analysis (Table 1). Each PCR reaction was carried out in $50 \mu \mathrm{l}$ reactions using the following conditions: 0.5 units of Taq Gold (Perkin Elmer) with the supplied reaction buffer $(5 \mu \mathrm{l})$; $0.1 \mathrm{mM}$ for each dNTP; $2 \mathrm{mM} \mathrm{MgCl}$ and $1 \mu \mathrm{M}$ of each primer. Fragments were amplified using a MJ Research programmable thermalcycler (PTC 100) with the following parameters: an initial denaturation at $93{ }^{\circ} \mathrm{C}(10 \mathrm{~min})$, followed by 40 cycles of denaturation at $93{ }^{\circ} \mathrm{C}(1 \mathrm{~min})$, annealing at $52{ }^{\circ} \mathrm{C}$ (1 min) and extending at $72{ }^{\circ} \mathrm{C}(2 \mathrm{~min})$. Following a final extension at $72{ }^{\circ} \mathrm{C}(10 \mathrm{~min})$, reactions were held at $4{ }^{\circ} \mathrm{C}$ until removed from the thermalcycler. Fragments were extracted from a $1 \%$ agarose gel using an Ultra-Free-MC 0.45 filter (Millipore) from which the supernatant was transferred to microcon-50 filter (Millipore) for purification. Automated sequencing was performed at Oregon State University Central Services Laboratory with an Applied Biosystems (373A) sequencer. Sequencing primers included MVZ-15, MVZ-16 and cytb2 (5'-AAACTGCAGCCCCTCAGAATGATATTTGTCCTCA-3'; Kocher et al. 1989). Sequences from fragments were aligned by eye using the Genetic Data Environment (Smith et al. 1992) and compared to a GenBank archived cytochrome $b$ sequence of Oregon slender salamander (U89625; Jackman et al. 1997).

MEGA 2.1 (Kumar et al. 2001) was used to perform preliminary data explorations and to obtain simple descriptive statistics (average pairwise genetic distances and standard errors) from the haplotypic data. Two methods were used to infer phylogenetic relationships among haplotypes observed in this study. First, we reconstructed a Neighbor-Joining phylogeny (Saitou and Nei 1987) of haplotypes using PAUP* 4.0b10 (Swofford 1998). Pairwise Jukes-Cantor genetic distances calculated for the haplotypes detected in our analyses were all small (range: 0.001240.04390 substitutions per site), indicating that use of more complicated models (with their associated greater variances) to account for multiple hits at nucleotide sites was not necessary (Nei and Kumar 2000 , p. 112). Thus, we relied on this simple measure of genetic distance for the NeighborJoining analysis. Second, we used PAUP* to perform Maximum Parsimony-based analyses of our data. Trees were evaluated using a heuristic search and the tree bisection-reconnection algorithm with starting trees obtained from 10 replicates of a random stepwise addition procedure. Bootstrap support for Neighbor-Joining and Maximum Parsimony trees was obtained from 1000 bootstrap replicates (Felsenstein 1985). A cytochrome $b$ sequence from the Inyo Mountain salamander (B. campi; GenBank accession U89626; Jackman et al. 1997), one of the closest extant phylogenetic relatives of the Oregon slender salamander (Yanev 1978; Marlow et al. 1979; Jockusch 1996), was used as an outgroup in each analysis.

\section{$R A P D$ procedure and analyses}

RAPD profiles of individuals were generated using protocols similar to those described in Haig et al. (1994, 1996, 1997, 2001). Sample sizes from each geographical location are listed in Table 1 (only 19 of the 22 sampling locations were examined for RAPD variation). PCR reactions were set up using the following reagent concentrations (25 $\mu \mathrm{l}$ volume): $10 \times$ buffer $(50 \mathrm{mM} \mathrm{KCl} ; 10 \mathrm{mM}$ Tris- $\mathrm{HCl}$ $\mathrm{pH} 9.0 ; 0.1 \%$ Triton X-100); $1.8 \mathrm{mM} \mathrm{MgCl}_{2}$; $0.1 \mathrm{mM}$ for each $\mathrm{dNTP} ; 0.2 \mu \mathrm{M}$ primer; $2 \mathrm{ng}$ template DNA; and 1 unit of Taq Polymerase (Promega). Reactions were run using an $\mathrm{MJ}$ 
Research thermal cycler (PTC-100) with the following parameters: 1 cycle at $93{ }^{\circ} \mathrm{C}(3 \mathrm{~min})$ followed by 45 cycles of denaturation at $93{ }^{\circ} \mathrm{C}$ ( $1 \mathrm{~min})$, annealing at $45^{\circ} \mathrm{C}(1 \mathrm{~min})$, and elongation at $72{ }^{\circ} \mathrm{C}\left(2 \mathrm{~min}\right.$.). A final elongation at $72{ }^{\circ} \mathrm{C}$ (10 min) completed the reaction, which was held at a constant $4{ }^{\circ} \mathrm{C}$ until removed from the cycler. Fifteen microlitres of each reaction was loaded in a $2.0 \%$ agarose gel (GibcoBRL; Ultrapure) and electrophoresed for $4 \mathrm{~h}(100 \mathrm{~V})$ in TBE $(90 \mathrm{mM}$ Tris base, $90 \mathrm{mM}$ Boric acid, $2 \mathrm{mM}$ EDTA, $\mathrm{pH}$ 8.0). Amplification products were sized using a $1 \mathrm{~kb}$ DNA ladder (GibcoBRL). Gels were stained with ethidium bromide $(1 \mu \mathrm{g} / \mathrm{ml})$ for $30 \mathrm{~min}$ and destained for $2 \mathrm{~h}$ in de-ionized water.

RAPD primers were assessed for variable bands by preliminary screening of 235 primers (from the Oligonucleotide Synthesis Laboratory, University of British Columbia; www.biotech.ubc.ca) utilizing two individuals from four populations (i.e., Post Canyon Road, Wildwood, Quartzville, Hidden Lake). These preliminary screens were used to identify specific RAPD primers that produced high quality markers (i.e., distinct, completely reproducible, well separated, and easily scored). Reproducibility was assessed for each RAPD marker using multiple replicate RAPD runs based on the same individuals from each population. After this preliminary screening, 15 primers that ultimately produced data for 46 high quality bands were chosen for generation of data for the full data set. Negative controls were run with each set of reactions to check for contamination products. Following gel analyses, the presence or absence of each RAPD marker phenotype was scored for each individual at the 46 loci examined. See electronic supplemental material, Figure 1 (Supplemental), for primer sequences used for analyses and gel images illustrating the specific RAPD markers scored in this study.

We characterized among-population genetic differentiation in several different ways. First, due to the dominant nature of the RAPD markers (Lynch and Milligan 1994; Zhivotovsky 1999), we used the allele frequency estimator of Lynch and Milligan (1994) to obtain estimates of the frequency of the null (recessive) allele at each locus. For the purposes of these estimates, each RAPD marker was assumed to be a Mendelian locus whose underlying genotypes corresponded to Hardy-Weinberg expectations. Based on these allele frequency estimates, we quantified the extent of genetic differentiation of sampling locations using the $F_{\mathrm{ST}}$ analog $\theta$ (Weir and Cockerham 1984) using the computer program TFPGA (Miller 1998a). Ninety-five percent confidence limits for $\theta$ were obtained through the use of a bootstrap procedure over loci consisting of 1000 resampling replications. Furthermore, we used TFPGA to calculate pairwise genetic distances between populations using the coancestry distance measure of Reynolds et al. (1983), which is essentially a simple transformation of pairwise $\theta$ estimates that functions well over relatively shortterm evolutionary time spans (Reynolds et al. 1983). These pairwise genetic distances were subsequently used for the UPGMA and Mantel test procedures described below. Second, rather than relying on the use of potentially biased allele frequencies estimated from dominant marker data (Lynch and Milligan 1994; Zhivotovsky 1999), we performed congruent sets of analyses based solely on variation in RAPD marker phenotypes (i.e., presence or absence) within and among populations. For these analyses, we used the computer program AMOVA-PREP (Miller 1998b) to assist with the preparation of input files that were subsequently analyzed using Arlequin 2.001 (Schneider et al. 2000). In Arlequin, we obtained an additional measure of overall and pairwise inter-populational genetic differentiation as $F_{\mathrm{ST}}$ values. $F_{\mathrm{ST}}$ estimates were calculated based on inter-individual genetic distances determined by the number of mismatched RAPD marker phenotypes between individuals. The significance of $F_{\mathrm{ST}}$ values (overall and pairwise) were determined through the use of a randomization procedure (random allocation of individuals and RAPD marker genotypes to populations) consisting of 3000 replicates. As with the coancestry distances obtained from TFPGA, pairwise $F_{\mathrm{ST}}$ values obtained for populations were subsequently used in the Mantel test and UPGMA procedures described below.

Pairwise genetic distances and $F_{\mathrm{ST}}$ values obtained from the procedures described above were used to determine if patterns of genetic differentiation among populations covaried with geographical distance. For these analyses, correlations between the pairwise genetic distance or $F_{\mathrm{ST}}$ matrices and a congruent geographical distance matrix were evaluated through the use of Mantel tests (Mantel 1967). Significance of the correlation between matrices was obtained through a ran- 
domization procedure (random reshuffling of the rows and columns of the geographical distance matrix) consisting of 5000 replicates. Furthermore, we obtained a graphical depiction of overall patterns of genetic dissimilarity of populations by constructing UPGMA dendrograms. For coancestry distances (Reynolds et al. 1983), we used TFPGA to perform analyses and further obtained node support through the use of a bootstrap procedure (sensu Felsenstein 1985) over loci based on 1000 replicates. UPGMA analyses of pairwise $F_{\mathrm{ST}}$ estimates obtained from Arlequin were performed using NTSYS-PC (Rohlf 1994).

\section{Results}

\section{MtDNA sequence analyses}

Results of cytochrome $b$ analyses suggested considerable mitochondrial sequence variation among the 22 locations examined. In total, we observed 18 unique haplotypes among populations (774 bp data) that were characterized by 48 variable sites (41 parsimony-informative) (Table 2). Geographical distributions of each haplotype are given in Table 1. In general, sequences were location-specific save for two haplotypes. One haplotype (haplotype B) was shared by all individuals from five different locations: Viento State Park (site 2), Ainsworth State Park (site 3), Train Tunnel (site 4), Bull Run (site 5), and Wildwood (site 7). A second haplotype (haplotype P) was shared among all individuals sequenced from two different locations: Quartzville (site 19) and Withycomb (site 20). Sequences from three individuals at each of the 22 locations revealed no within-location variation with the exception of Thomas Creek (site 16), which contained two different (but closely related) haplotypes (haplotypes L and M). Overall, despite limited withinlocation sampling of individuals, our results suggest that haplotype diversity within populations is small relative to among population haplotype diversity.

Phylogenetic analyses of haplotype sequences produced similar results for both methods of inference. For Maximum Parsimony analyses, 30 most parsimonious trees of length 106 were found (consistency index $=0.8396$ ). Variation in topologies of these 30 equal-length trees was characterized by subtle changes in the arrangement of

Table 2. Mitochondrial DNA sequence variation of the cytochrome $b$ gene (774 bp) in 18 haplotypes found in Oregon slender salamanders

\begin{tabular}{|c|c|}
\hline Haplotype & Sequence position \\
\hline & $\begin{array}{l}000000011111112222222333344445555555666667777777 \\
011456914457790112568012733690355578113780133566 \\
567024382512512470320705446935801740691094324825\end{array}$ \\
\hline A & TGAATCTTCCCCGATAATCCGGGCTGCTGGCAAGTTAGCGGTTGCCGE \\
\hline B & $\ldots \ldots \ldots \ldots \ldots \ldots \ldots \ldots \ldots \ldots \ldots \ldots \ldots \ldots$. \\
\hline $\mathrm{C}$ & $\ldots \ldots \ldots \ldots \ldots$. $\ldots \ldots \ldots \ldots \ldots \ldots \ldots \ldots \ldots \ldots \ldots$ \\
\hline D & \\
\hline $\mathrm{E}$ & 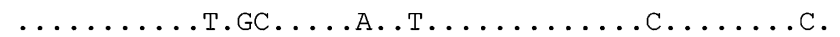 \\
\hline F & 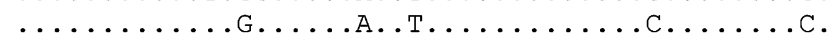 \\
\hline G & CAGTCTCC.TTT.GCCG.T..А.T.A.CAATGG. .CGCT..CC...С. \\
\hline $\mathrm{H}$ & CAGTCTC..TTT. GCCG.TT.A.TCA. CAATGG. . СGCT. . СC...С. \\
\hline I & 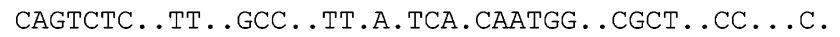 \\
\hline $\mathrm{J}$ & CAGTCTC..TTT.GCCG.TT.A.T.A.CAATGG..CGCT..CC...С. \\
\hline $\mathrm{K}$ & CAGTCTC..TTT.GCCG.T..А.T.A.CAATGG..СGCT..СC...С. \\
\hline $\mathrm{L}$ & 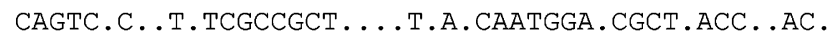 \\
\hline M & CAGTC.C. .T.TCGCCG.T... . .A. CAATGGA. CGCT. ACC. . AC. \\
\hline $\mathrm{N}$ & 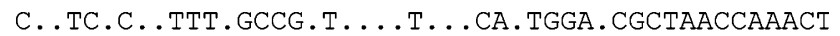 \\
\hline 0 & CAGTCTCC.TTT.GCCG.T..A.T. . CAATGGA.CGCT.ACC...С. \\
\hline $\mathrm{P}$ & CAGTCTC..TTT.GCCG.T..А.T. . CAATGGA.CGCT. ACC...С. \\
\hline Q & CA.TC.C.TT.T.GCCGCT...АT. .TC..TGG.CC.CT..CC..С. \\
\hline $\mathrm{R}$ & 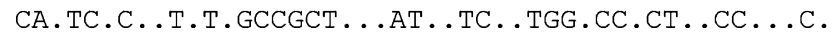 \\
\hline
\end{tabular}

Data from 48 variable sites relative to haplotype A (Genbank accession number U98773) are shown. 
haplotypes separated by short branches. Neighbor-Joining analyses produced a single tree with a sum of branch lengths of 0.160 . Bootstrap analyses of topologies generated by both methods gave similar topologies that were mainly characterized by the presence of two distinct clades corresponding to northern and southern-distributed haplotypes (Figures 2 and 1). The northern clade was comprised of haplotypes found among the 10 northern-distributed population (haplotypes A-F; Tables 1 and 2) and was supported by 81 and $64 \%$ of bootstrap replicates in Neighbor-Joining and Maximum Parsimony analyses, respectively. The southern clade contained haplotypes found among the 12 southern-distributed populations (haplotypes $\mathrm{G}-\mathrm{R}$; Tables 1 and 2). This grouping was supported by 100 and $99 \%$ of bootstrap replicates in Neighbor-Joining and Maximum Parsimony analyses, respectively. Nucleotide diversity was lower in the northern clade compared to the southern clade. Among the six northern haplotypes, average pairwise nucleotide differences among haplotypes $(d=3.53$, S.E. $=1.18)$ was over 2-fold lower than that seen among 12 haplotypes found in southern populations $(d=8.94$, S.E. $=1.79)$. Both values were substantially lower than average pairwise nucleotide differences among all 18 unique haplotypes detected in our analyses $(d=21.44$, S.E. $=2.53)$.

\section{RAPD analyses}

Analysis of our 46 RAPD markers suggested that there is substantial nuclear genetic variation among the locations examined. When allele frequencies were estimated from dominant marker data, we obtained an average $\theta$ value of 0.306 (upper confidence limit $=0.351$, lower confidence limit $=0.260$ ). This value was comparable to the overall estimate of $F_{\mathrm{ST}}$ obtained from analyses of marker phenotype variation obtained from Arlequin $\left(F_{\mathrm{ST}}=0.347, P<0.001\right)$. Although our analyses suggested relatively high average levels of population differentiation, we note that there was also considerable variability in pairwise genetic distances and $F_{\mathrm{ST}}$ values. For example, coancestry distances between populations ranged from 0.101 to 0.510 , while pairwise $F_{\mathrm{ST}}$ estimates ranged from 0.098 to 0.539 . All pairwise $F_{\mathrm{ST}}$ values were significantly different from zero $(P<0.003)$. Overall, values of coancestry distances and $F_{\mathrm{ST}}$ values were highly correlated ( $r=0.893, P<0.001)$, indicating that analyses based on estimated allele frequencies give results generally comparable to ones conducted solely on RAPD marker phenotypes.

Results of Mantel tests suggested the pattern of divergence among populations reflected an isolation-by-distance pattern (Figure 3). Correlations
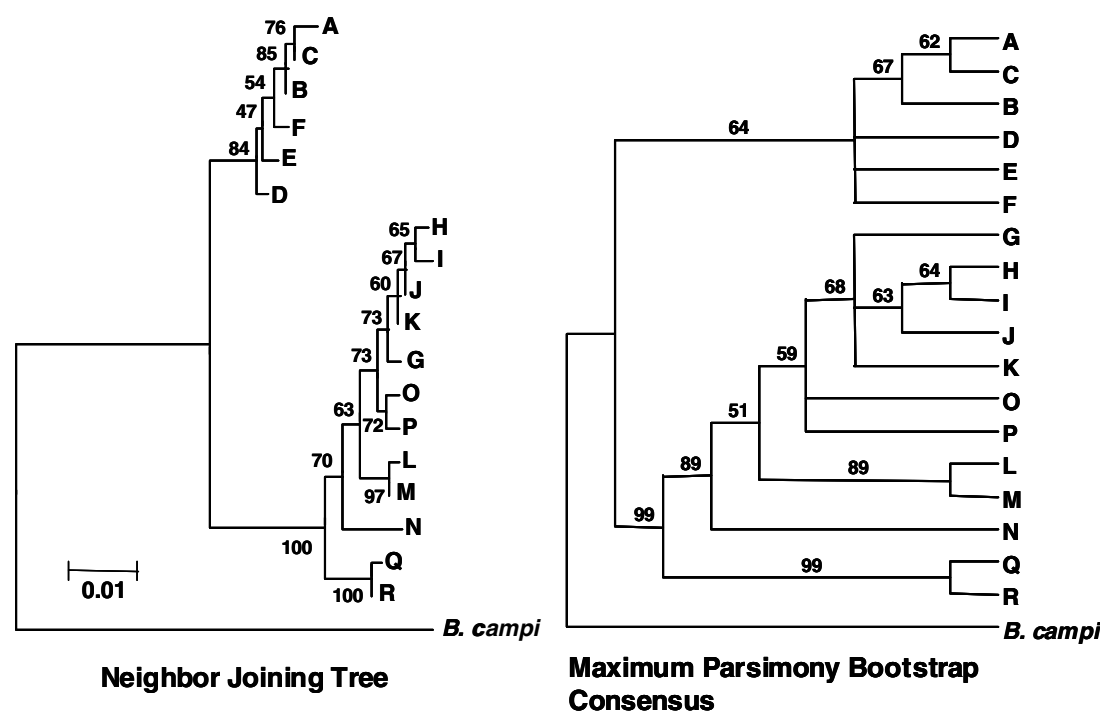

Figure 2. Neighbor-Joining phylogram and Maximum Parsimony majority-rules bootstrap consensus tree obtained from analyses of 18 cytochrome oxidase subunit I haplotypes in Oregon slender salamanders (Table 2). Numbers on branches reflect the percent of 1000 bootstrap replicates that supported the given topology. Geographical locations of each haplotype are given in Table 1. 


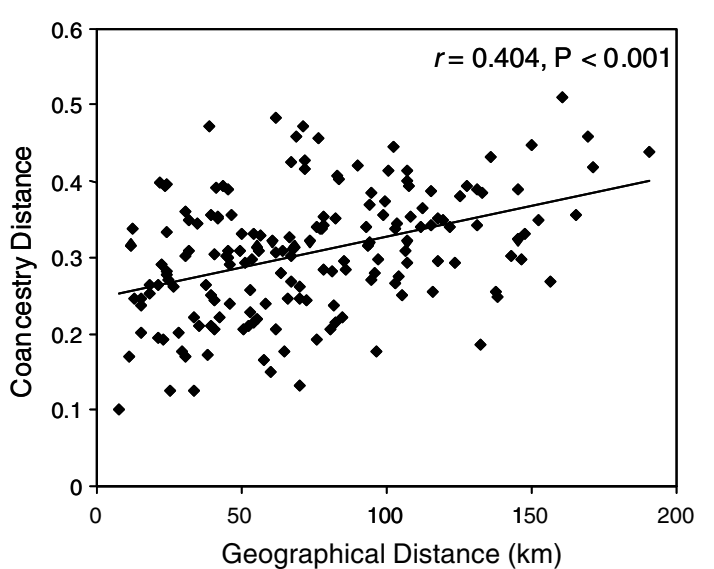

Figure 3. Scatterplot of pairwise coancestry genetic distances (based on estimated allele frequencies) and geographical distances of populations obtained from analyses of 46 RAPD markers in Oregon Slender Salamanders. Comparable results were obtained when genetic distances were based on pairwise $F_{\mathrm{ST}}$ estimates calculated from raw marker phenotype data $(r=0.433, P<0.001)$.

between geographical distances and pairwise $F_{\mathrm{ST}}$ values were significant ( $r=0.433, P<0.001)$, and produced results that were comparable to the correlation observed when coancestry distances were used to perform the analysis ( $r=0.404$, $P<0.001)$. UPGMA analyses performed on both distance matrices produced dendrograms with relatively similar topologies (Figure 4), however, bootstrap analyses performed on the dendrogram generated from coancestry distances indicated few nodes with strong support.

\section{Discussion}

\section{Mitochondrial analyses}

Slender salamanders are comprised of two deep branching subgenera. Batrachoseps wrighti, along with the Inyo Mountain salamander (B. campi; found in eastern California) and an additional currently undescribed species from California comprise the monophyletic subgenus Plethopsis that is a sister group to the taxa-rich subgenus Batrachoseps (Jackman et al. 1997; Jockusch and Wake 2002). Previously, Jockusch and Wake (2002) reported a relatively low amount of cytochrome $b$ divergence $(0-1.8 \%$; Kimura 2-parameter distances) among three southern $B$. wrighti salamander populations compared to the much

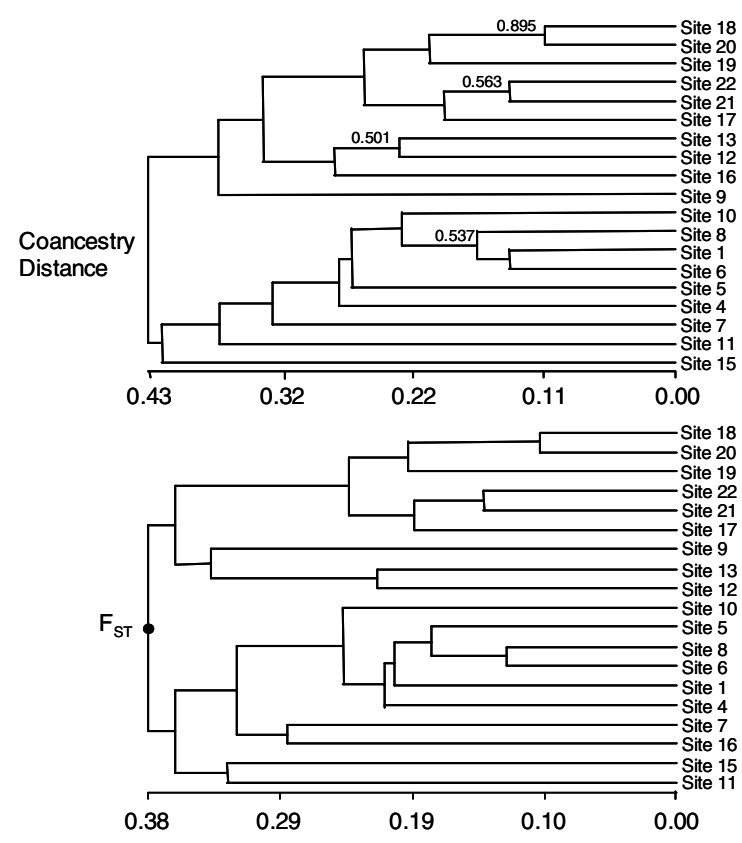

Figure 4. Midpoint-rooted UPGMA dendrograms of pairwise genetic distance between populations based on 46 RAPD loci. Relatively similar topologies were obtained when genetic distances were based on allele frequencies estimated from dominant marker data (Coancestry distances) and when raw marker phenotype data (presence or absence) were used to obtain pairwise $F_{\text {ST }}$ estimates. Numbers on branches of the coancestry distance tree reflect the proportion of 1000 bootstrap replicates that supported the topology. Only bootstrap values greater than 0.5 are shown.

higher values seen among populations of species within the subgenus Batrachoseps. Our results for the Oregon slender salamander, based on more extensive sampling of geographical locations and including populations from the northern extent of their range (up to $190 \mathrm{~km}$ further north), revealed substantially more haplotypes (18 total) and greater haplotype diversity (average percent pairwise nucleotide differences $=3.1 \%$ uncorrected).

Our analyses also revealed the presence of two well-supported haplotype lineages that encompassed alleles detected in northern versus southern-distributed populations (Figures 1 and 2 and Table 1). The average between-clade genetic distance of haplotypes was $3.6 \%$ (uncorrected; S.E. $=0.006$ ). While this observed level of differentiation may not be sufficient to warrant taxonomic changes (other evidence should also be considered), it suggests that this divergence occurred some time ago, perhaps due to vicariance. Using the "molecular clock" feature in MEGA2 
(Kumar et al. 2001), the Neighbor-Joining tree of haplotypes based on Jukes-Cantor genetic distances, and the commonly used vertebrate evolutionary clock rate of $2 \%$ divergence per million years (Brown and Simpson 1982), our data suggest that allelic differentiation of clades occurred during the early Pliestocene ( $\sim 1$ mya). Application of the substantially slower clock rates often attributed to amphibians and reptiles (Avise et al. 1992; Johns and Avise 1998) would easily place divergence times in the Pliocene. Furthermore, our data indicate that the northern part of $B$. wrighti's range may have been more recently colonized relative to the south. Indeed, we detected six unique closely related haplotypes (average pairwise nucleotide differences: $d=3.53, \quad$ S.E. $=1.18$ ) among the 10 populations containing haplotypes found in the northern clade. In contrast, the 12 southern-distributed populations contained 12 haplotypes that were on average much more divergent (average pairwise nucleotide differences: $d=8.94$, S.E. $=1.79$ ) than those found in the northern group. Overall, this pattern suggests that there has been substantially less time for novel mutations to accumulate within northern populations. Furthermore, in contrast to southern populations, 5 of 10 northern populations surveyed contained identical haplotypes. This potentially indicates that Oregon slender salamanders may have relatively recently extended their range up to the Columbia River.

\section{RAPD analyses and comparisons with mitochondrial data}

As with the mitochondrial sequence data, our RAPD analyses suggested extensive genetic structure among Oregon slender salamander populations. RAPD variation among the populations examined indicated high average levels of population differentiation $\left(\theta=0.306, F_{\mathrm{ST}}=0.347\right)$ as well as substantial variation in pairwise genetic distances among locations. Furthermore, UPGMA analyses of pairwise genetic distances among populations produced generally similar topologies regardless of genetic distance measure employed (Figure 4). However, in contrast to our mitochondrial sequence data (Figure 2), bootstrap analysis of the coancestry distance-based tree revealed little overall branch support and suggested no particularly deep clusters of nuclear genetic variation among populations. Recent simulation studies (Hollingsworth and Ennos 2004) have suggested that individual-based (as opposed to population-based) Neighbor-Joining trees derived from dominant markers such as RAPDs are likely to produce unresolved, star-like topologies that illustrate no population genetic structuring when data from $<50$ markers are used to produce trees. It is uncertain at this time as to whether or not this conclusion also applies to UPGMA topologies and the population-based (as opposed to individualbased) analyses included in this study. We note, however, that results of Mantel tests suggested a generalized pattern of isolation by distance where geographically proximate populations showed smaller genetic distances than distal populations (Figure 3). As a result, the lack of strong structure in UPGMA trees may simply reflect the difficulty of representing relatively continuous patterns of genetic distances suggested in Figure 3 via algorithms (i.e., UPGMA) designed to recapture results of bifurcating processes.

Population structure is generally influenced by gene flow and random genetic drift; however, in studies of natural populations it is often difficult to determine their relative contributions. Furthermore, gene flow estimates from $F_{\mathrm{ST}}$ or its analogs are often inappropriate (e.g., Whitlock and McCauley 1999) since they can be confounded by historical processes such as vicariance or range expansions (Bossart and Prowell 1998). In our study of the Oregon slender salamander, inferences about specific processes that have influenced genetic structure become particularly difficult given that analyses of mitochondrial sequences and nuclear RAPD markers apparently produced different results. We note, however, that two non-exclusive hypotheses can be invoked to reconcile apparent discrepancies between our data sets.

First, differences between data sets may reflect the varying influence of genetic drift on mitochondrial and nuclear genomes. Mitochondrial genes, due to their uni-parental (maternal) inheritance and haploid genotypes, have a 4 -fold reduced effective population size relative to their diploid/bi-parentally inherited nuclear counterparts (Hartl and Clark 1989). Given this reduced effective population size, mitochondrial alleles are much more susceptible to processes such as genetic drift and are therefore more likely to demonstrate 
strong patterns of genetic structure relative to nuclear alleles over comparable evolutionary time scales. As a result, our combined analyses of the mitochondrial and RAPD data may suggest an ancestral overall pattern of isolation by distance of populations that may have resulted from range expansion or historical phylogeographic barriers to gene flow. Under this scenario, sufficient time has elapsed following isolation for complete sorting of mitochondrial lineages among populations and geographical regions. In contrast, nuclear loci, given their greater effective population sizes, may have retained sufficient variation within populations to maintain the ancestral correlation between genetic and geographical distances. We note that the Columbia River became repeatedly blocked during the Pliocene and Pleistocene. This process significantly deflected the main river channel both north and south of the current mainstem on several different occasions (Fecht et al. 1987; Heller et al. 1987). The southern-most reroute of the channel occurred in the region between the northern and southern mitochondrial haplotype discontinuity (Figure 1) and may have provided a northern barrier to dispersal. However, as the river shifted from its historical southern position to its current location during the early Pleistocene, $B$. wrighti may have expanded its range in concert to establish the current geographical distribution of this species. Additionally, we must consider the possibility that a southern shift in the river channel may have at one point isolated northern and southern populations by acting as a strong barrier to gene flow. Therefore, the contemporary pattern observed in mitochondrial data may simply be the signature of a historical phylogeographical barrier. Concordantly, if gene flow is minimal in B. wrighti, we would likely expect the pattern of nuclear genetic variation to demonstrate similar patterns of divergence over the long-term course of evolutionary history.

In contrast to the hypothesis described above, we suggest that differences in patterns from mitochondrial and nuclear data may simply reflect different dispersal tendencies of male and female salamanders. If males have larger home ranges than females and tend to disperse over larger distances, then we may expect to observe the patterns revealed in this study. Indeed, if males routinely or even episodically facilitate genetic exchanges between populations, they would only be capable of mediating transfer of nuclear alleles (i.e., RAPD markers in this study); the maternally inherited mitochondrial alleles would not be influenced by this process. Male-biased gene flow has recently been invoked to explain discordances between nuclear and mitochondrial markers in a phylogenetic study of Batrachoseps (Jockusch and Wake 2002), and as an overall rule, male salamanders have larger home ranges than females (Stebbins and Cohen 1995). Therefore, despite previous observational data from the California slender salamander (B. attenuates) suggesting limited dispersal in Batrachoseps (Hendrickson 1954), we encourage initiation of new long-term mark-recapture studies for $B$. wrighti designed to evaluate sex-specific dispersal behavior. Alternatively, we suggest that careful analyses of sex-specific patterns of within-location genetic diversity be used to determine if differences in dispersal behaviors exist between sexes (e.g., Hansen et al. 2003; Hapke et al. 2001). Generation of these new data will ultimately provide support for or help refute hypotheses about the relative role of dispersal and its influence on genetic structure in the Oregon slender salamander.

\section{Conservation implications and conservation unit designation}

A number of conflicting definitions for conservation units have been proposed for prioritizing conservation efforts (e.g., Ryder 1986; Waples 1991; Dizon et al. 1992; Moritz 1994a, b; Vogler and Desalle 1994; Bowen 1998, Crandall et al. 2000). Although all approaches share the common goal of preserving genetic diversity, recent controversies have mainly centered on the conservation of phylogenetic diversity (e.g., Moritz 2002) versus conservation of adaptive genetic variation and phenotypes (e.g., Crandall et al. 2000), with other authors advocating the application of these differing criteria in a flexible manner on a case-bycase basis (Fraser and Bernatchez 2001). We note, however, that there is currently little ecological, life history, or quantitative genetic data available for the Oregon slender salamander that would permit designation of conservation units based on adaptive phenotypic attributes. In contrast, genetic data generated in this study specifically lend themselves to interpretation under the commonlyapplied conservation unit concept of Moritz 
(Moritz 1994a, b; Moritz et al. 1995) which defines an Evolutionary Significant Unit (ESU) as requiring reciprocal monophyly of mitochondrial DNA alleles and significant differentiation at nuclear alleles.

Based on Moritz's definition, our data for $B$. wrighti suggest the presence of two distinct conservation units that correspond to northerndistributed versus southern-distributed groups of populations. However, given the absence of any apparent phylogeographic barriers among the two groups, designation of separate management units may not be prudent at this time. Furthermore, we have proposed two distinct (albeit non-exclusive) hypotheses that can be used to explain our data and note that the validity of conservation unit designations ultimately depends on the relative contribution of the underlying mechanisms indicated by each hypothesis.

Under the first hypothesis, we suggested that the strong phylogeographic structure illustrated by mitochondrial sequence data, in contrast to nuclear data, was due to the different effects of genetic drift on mitochondrial versus nuclear genomes in a system where gene flow among populations is minimal. Based on this scenario, it is expected that nuclear alleles will eventually show a pattern similar to that observed for mitochondrial haplotypes given sufficient time for lineage sorting. If this hypothesis is largely correct, then designation of separate conservation units will provide an important framework for prioritizing conservation efforts for this species under the Northwest Forest Plan (US Forest Service and US Bureau of Land Management 1994). By focusing forest management efforts with respect to management unit designations, it may be possible to mitigate different threats to $B$. wrighti's persistence across their range.

In contrast, if our data instead reflect a situation where male-mediated gene flow promotes genetic exchange between populations, then designation of separate conservation units may be unwarranted. Under this scenario, the strong phylogeographical structuring observed in the mitochondrial data is mainly attributable to maternal philopatry and exchange of nuclear alleles among populations is facilitated by male salamanders. Thus, in contrast to the genetic driftinfluence hypothesis described above, we would likely never expect to observe concordance of nu- clear and mitochondrial data if gene flow is an ongoing influence on genetic structure. Given that the vertebrate mitochondrial genome is very small relative to the nuclear genome, it is perhaps potentially inappropriate to designate separate conservation units (northern versus southern) based on the differentiation of a very small proportion (i.e., mitochondrial versus nuclear) of the total genetic information in this species. We note, however, if male mediated gene flow is primarily responsible for the transfer of alleles across the landscape, then management of critical Oregon slender salamander habitat is no less imperative. Indeed, even if males were to liberally move among habitat patches, they would be unable to recolonize previously disturbed habitats or establish new populations in the absence of their philopatric female counterparts.

\section{Acknowledgments}

We are most grateful to a number of individuals who contributed to the success of this project. We thank J. Beatty, C. Corkran, T. Dove, J. Dwyer, J. England, M. Hee, L. Larsen, Y. Lee, H. Packard, and the OSU Herpetology Class of 1994 for assistance in sample collection. Laboratory assistance was provided by N. Adair, M. Boriss, M. Hee, P. Lybarger, T. Mullins, M. Rhodes, S. Warnock, and B. Wright. The manuscript greatly benefited from the suggestions of J. Beatty, L. Gorman, M. Hee, D. Kesler, T. Mullins, O. Taft, D. Vesely, and the "USU Herp Group". This project was funded by the USGS Forest and Rangeland Ecosystem Science Center.

\section{References}

Alexandrino J, Froufe E, Arntzen JW, Ferrand N (2000) Genetic subdivision, glacial refugia and postglacial recolonization in the golden-striped salamander, Chioglossa lusitanica (Amphibian: Urodela). Mol. Ecol., 9, 771-781.

Avise JC (1992) Molecular population structure and the biogeographic history of a regional fauna: A case history with lessons for conservation biology. Oikos, 63, 62-76.

Avise JC (1994) Molecular Markers, Natural History and Evolution. Chapman \& Hall, New York.

Avise JC, Arnold J, Ball RM, Bermingham E, Lamb T, Neigel JE, Reeb CA, Saunders NC (1987) Intraspecific phylogeography: The mitochondrial DNA bridge between population genetics and systematics. Ann. Rev. Ecol. Syst., 18, 489-522. 
Avise JC, Bowen BW, Lamb T, Meylan AB, Bermingham E (1992) Mitochondrial DNA evolution at a turtles pace: Evidence for low genetic variability and reduced microevolutionary rates in the testudines. Mol. Biol. Evol., 9, 457-473.

Baker VR, Barker RC (1985) Cataclysmic late Pleistocene flooding from Glacial Lake Missoula: A review. Quat. Sci. Rev., 4, 1-41.

Bohonak AJ (1999) Dispersal, gene flow, and population structure. Q. Rev. Biol., 74, 21-45.

Bossart JL, Prowell DP (1998) Genetic estimates of population structure and gene flow: Limitations, lessons, and new directions. Trends Ecol. Evol., 13, 202-206.

Bowen B (1998) What is wrong with ESUs?: The gap between evolutionary theory and conservation principles. J. Shellfish Res., 17, 1355-1358.

Brown GG, Simpson MV (1982) Novel features of animal mtDNA evolution as shown by sequences of two rate cytochrome oxidase subunit II genes. Proc. Natl. Acad. Sci. USA, 79, 3246-3250.

Bury BR, Corn PS (1988) Douglas-fir forests in the Oregon and Washington Cascades: Relation of the herptofauna to stand age and moisture. In: Management of Amphibians, Reptiles, and Small Mammals in North America, General Technical Report RM-166 (eds. Szaro RC, Severson KE, Patton DR), pp. 11-22. USDA Forest Service, Rocky Mountain Forest and Range Experiment Station, Fort Collins.

Cooper ML (2000) Random amplified polymorphic DNA analysis of southern brown bandicoot (Isoodon obesulus) populations in western Australia reveals genetic differentiation related to environmental variables. Mol. Ecol., 9, 469-479.

Crandall KA, Bininda-Emonds ORP, Mace GM, Wayne RK (2000) Considering evolutionary processes in conservation biology. Trends Ecol. Evol., 15, 290-295.

Dizon AE, Lockyer C, Perrin WF, Demaster DP, Sisson J (1992) Rethinking the stock concept: A phylogenetic approach. Conserv. Biol., 6, 24-36.

Doukakis P, Birstein VI, Ruban GR, Desalle R (1999) Molecular genetic analysis among subspecies of two Eurasian sturgeon species, Acipenser baerii and A. stellatus. Mol. Ecol., 8, 117-127.

Fecht KR, Reidel SP, Tallman AM (1987) Paleodrainage of the Columbia River system on the Columbia Plateau of Washington State-A summary. In: Selected Papers on the Geology of Washington Bulletin 77 (ed. Shuster JE), pp. 219-248. Washington Division of Geology and Earth Resources.

Felsenstein J (1985) Confidence limits on phylogenies: An approach using the bootstrap. Evolution, 39, 783-791.

Frazer DJ, Bernatchez L (2001) Adaptive evolutionary conservation: Towards a unified concept for defining conservation units. Mol. Ecol., 10, 2741-2752.

Gilbert FF, Allwine R (1991) Terrestrial amphibian communities in the Oregon Cascade Range. In: Wildlife and Vegetation of Unmanaged Douglas-fir Forests, General Technical Report NW-285 (eds. Ruggiero LF, Aubry KB, Carry AB, Huff M), pp. 340-350. USDA Forest Service, Pacific Northwest Station, Portland, Oregon.

Haig SM, Rhymer JM, Heckel DG (1994) Population differentiation in randomly amplified polymorphic DNA of Redcockaded Woodpeckers. Mol. Ecol., 3, 581-595.

Haig SM, Bowman R, Mullins TD (1996) Population structure of Red-cockaded woodpeckers in south Florida: RAPDs revisited. Mol. Ecol., 5, 725-734.
Haig SM, Gratto-Trevor CL, Mullins TD, Colwell MA (1997) Population identification of western hemisphere shorebirds throughout the annual cycle. Mol. Ecol., 6, 413-427.

Haig SM, Wagner RS, Forsman ED, Mullins TD (2001) Geographic variation and genetic structure in Spotted Owls. Conserv. Genet., 2, 25-40.

Haig SM, Forsman ED, Mullins TD (in press) Subspecies relationships and genetic structure in the Spotted Owl. Conserv. Genet.

Hansen LA, Mathews NE, Hansen RW, Vander Lee BA, Lutz RS (2003) Genetic structure of striped skunks (Mephitis mephitis) on the Southern High Plains of Texas. West. N. A. Nat., 63, 80-87.

Hapke A, Zinner D, Zischler H (2001) Mitochondrial DNA variation in Eritrean hamadryas baboons (Papio hamadryas hamadryas): life history influences population genetic structure. Behav. Ecol. and Sociobiol., 50, 483-492.

Hartl DL, Clark AG (1989) Principles of Population Genetics, 2nd edn. Sinauer Associates, Sunderland, MA.

Heller PL, Tabor RW, Suczek CA (1987) Paleographic evolution of the United states Pacific Northwest during Paleogene time. Can. J. Earth Sci., 24, 1652-1667.

Hendrickson JR (1954) Ecology and systematics of salamanders of the genus Batrachoseps. Univ. Calif. Publ. Zool., 54, 1-46.

Hollingsworth PM, Ennos RA (2004) Neighbour joining trees, dominant markers, and population genetic structure. Heredity, 92, 490-498.

Jackman TR, Applebaum G, Wake DB (1997) Phylogenetic relationships of Bolitoglossine salamanders: A demonstration of the effects of combining morphological and molecular data sets. Mol. Biol. Evol., 14, 883-891.

Jockusch EL (1996) Evolutionary Studies in Batrachoseps and Other Plethodontid Salamanders: Correlated Character Evolution, Molecular Phylogenetics, and Reaction Norm Evolution. PhD dissertation, University of California, Berkeley, USA.

Jockusch EL, Wake DB (2002) Falling apart and merging: Diversification of slender salamanders (Plethodontidae: Batrchoseps) in the American West. Biol. J. Linnean Soc., 76, 361-391.

Johns GC, Avise JC (1998) A comparative summary of genetic distances in the vertebrates from the mitochondrial cytochrome $b$ gene. Mol. Biol. Evol., 15, 1481-1490.

Kimberling DN, Ferrarira AR, Shuster SM, Keim P (1996) RAPD marker estimation of genetic structure among isolated northern leopard frog populations in the south-western USA. Mol. Ecol., 5, 521-529.

Kocher TD, Thomas WK, Edwards SV, Paabo S, Villablanca FX, Wilson AC (1989). Dynamics of mitochondrial DNA evolution in animals: Amplifications and sequencing with conserved primers. Proc. Natl. Acad. Sci. USA, 86, 6196-6200.

Kumar S, Tamura K, Jakobsen IB, Nei M (2001) MEGA2: Molecular Evolutionary Genetics Analysis Software. Bioinformatics, 17, 1244-1245.

Lamb T, Avise JC, Gibbons JW (1989) Phylogeographic patterns in mitochondrial DNA of the desert tortoise (Xerobates agassizi), and evolutionary relationships among the North American gopher tortoises. Evolution, 43, 76-87.

Lynch M, Milligan BG (1994) Analysis of population genetic structure with RAPD markers. Mol. Ecol., 3, 91-99.

Mantel NA (1967) The detection of disease clustering and generalized regression approach. Cancer Res., 27, 209-220. 
Marlow RW, Brode JM, Wake DB (1979) A new salamander, genus Batrachoseps, from the Inyo Mountains of California, with a discussion of relationships in the genus. Nat. Hist. Mus. Los Angel. Co. Contrib. Sci., 308, 1-17.

Marshall DB, Chilcote M, Weeks H (1992) Sensitive Vertebrates of Oregon. Oregon Department of Fish and Wildlife. Portland, Oregon.

McGroder MF (1991) Reconciliation of two-sided thrusting, burial metamorphism, and diachronous uplift in the Cascades of Washington and British Columbia. Geol. Soc. of Am. Bull., 103, 189-209.

Miller MP (1998a) Tools for Population Genetic Analyses (TFPGA). Computer software distributed by author. http:// bioweb.usu.edu/mpmbio.

Miller MP (1998b) AMOVA-PREP. Computer software distributed by author. http://bioweb.usu.edu/mpmbio.

Miller MP, Blinn DW, Keim P (2002). Correlations between observed dispersal capabilities and patterns of genetic differentiation in populations of four aquatic insect species from the Arizona White Mountains, USA. Freshwater Biol. 47, 1660-1673.

Moritz C (1994a) Applications of mitochondrial DNA analysis in conservation: A critical review. Mol. Ecol., 3, 401-411.

Moritz C (1994b) Defining "Evolutionary Significant Units" for conservation. Trends Ecol. Evol., 9, 373-375.

Moritz C (2002) Strategies to protect biological diversity and the evolutionary processes that sustain it. Syst. Biol., 51, 238-254.

Moritz C, Schneider CJ, Wake DB (1992) Evolutionary relationships within the Ensatina eschscholtzii complex confirm the ring species interpretation. Syst. Biol., 41, 273-291.

Moritz C, Lavery S, Slade R (1995) Using allele frequency and phylogeny to define units for conservation and management. Am. Fish. Soc. Symp. 17, 249-262.

Nei M, Kumar S (2000) Molecular Evolution and Phylogenetics. Oxford University Press, New York.

Nussbaum RA, Brodie ED Jr., Storm RM (1983) Amphibians and Reptiles of the Pacific Northwest. University Press of Idaho, Idaho.

Oregon Department of Fish and Wildlife (1997) Oregon Department of Fish and Wildlife List of Sensitive Species. Portland, Oregon.

Phillips CA (1994) Geographic distribution of mitochondrial DNA variants and the historical biogeography of the spotted salamander, Ambystoma maculatum. Evolution, 48, 597-607.

Phillips CA, Suau G, Templeton AR (2000) Effects of Holocene climate fluctuation on mitochondrial DNA variation in the ringed salamander, Ambystoma annulatum. Copeia, 2000, 542-545.

Prior KA, Gibbs HL, Weatherhead PJ (1997) Population genetic structure in the black rat snake: Implications for management. Conserv. Biol., 11, 1147-1158.

Reynolds J, Weir BS, Cockerham CC (1983). Estimation of the coancestry coefficient: Basis for a short-term genetic distance. Genetics, 105, 767-779.

Rohlf FJ (1994) NTSYS-pc: Numerical Taxonomy and Multivariate Analysis System, Version 1.8. Exeter Software, Setauket, New York.
Routman E, Wu R, Templeton AR (1994) Parsimony, molecular evolution, and biogeography: The case of the North American giant salamander. Evolution, 47, 1799-1809.

Ryder OA (1986) Species conservation, and systematics: The dilemma of subspecies. Trends Ecol. Evol., 1, 9-10.

Saitou N, Nei M (1987) The neighbour-joining method: A new method for reconstructing phylogenetic trees. Mol. Biol. Evol., 4, 406-425.

Sambrook J, Fritsch EF, Maniatis T (1989) Molecular Cloning: A Laboratory Manual, 2nd edn. Cold Spring Harbor Laboratory Press, New York.

Schneider S, Roessli D, Excoffier L (2000) Arlequin: A Software for Population Genetics Data Analysis. Computer software distributed by authors, Geneva.

Smith SW, Wang C, Gillevet PM, Gilbert W (1992) Genetic Data Environment and Harvard Genome Database. Genome Mapping and Sequencing, Cold Spring Harbor Laboratory. http://fastlink.nih.gov/gde_sw.html.

Stebbins RC, Cohen NW (1995) A Natural History of Amphibians. Princeton University Press, Princeton, NJ.

Swofford DL (1998) Phylogenetic Analysis Using Parsimony (PAUP), Version 4,0*, beta. Sinauer Associates, Sunderland.

Tan A, Wake D (1995) MtDNA phylogeography of the California newt, Taricha torosa (Caudata, Salamandridae). Mol. Phylogenet. Evol., 4, 383-394.

Tanner W (1953) Notes on the life history of Plethopsis wrightii Bishop. Herpetologica, 9, 139-140.

US Forest Service and US Bureau of Land Management (1994) Final Supplemental Environmental Impact Statement on Management of Habitat for Inter-successional and Old Growth Forest Related Species Within the Range of the Northern Spotted Owl. Portland, Oregon.

Vogler AP, DeSalle R (1994) Diagnosing units of conservation management. Conserv. Biol., 8, 354-363.

Walker D, Moler PE, Buhlmann KA, Avise JC (1998) Phylogeographic uniformity in mitochondrial DNA of the snapping turtle (Chelydra serpentina). Anim. Conserv., 1, 55-60.

Waples RS (1991) Pacific Salmon, Onchorynchus spp., and the definition of "species" under the Endangered Species Act. Mar. Fish. Rev. 53, 11-22.

Weir BS, Cockerham CC (1984) Estimating $F$-statistics for the analysis of population structure. Evolution, 38, 1358-1370.

Whitlock MC, McCauley DE (1999) Indirect measures of gene flow and migration: $\left.F_{\mathrm{ST}}<>1 /(4 \mathrm{Nm})+1\right)$. Heredity, 82, 117-125.

Wood RM, Raley ME (2000) Cytochrome $b$ sequence variation in the Crystal darter Crystallaria asprella (Actinoptergii: Percidae). Copeia, 2000, 20-26.

Yanev KP (1978) Evolutionary Studies of the Plethodontid Salamander Genus Batrachoseps. PhD thesis, University of California, Berkeley, USA.

Zhivotovsky LA (1999) Estimating population structure in diploids with multilocus dominant DNA markers. Mol. Ecol., 8, 507-514. 